\title{
Hibridação e a "estética da hipervenção"
}

Denize Correa Araujo Universidade Tuiuti do Paraná 
Na verdade, o filmmaker Victor Masayesva é produto de uma cultura híbrida, o que fica transparente em seu modo de representar certos elementos indígenas em linguagem tecnológica considerada, como ele próprio diz, "tecnologia de branco". Seria difícil considerar o filme como pertencente à estética do Dogma, por exemplo, pois apesar de os atores serem amadores e de os cenários serem inicialmente naturais, a edição computadorizada não endossa o aspecto natural, criando diversos efeitos, como enormes pedras que se abrem, pinturas rupestres que se movem, se transformam em búfalos e correm livremente pelos campos até serem abatidas pelos brancos, danças estereotipadas em filmes de Hollywood que se misturam com as árvores, enfim, diversos tipos de efeitos que criam uma nova estética, colocando os nativos americanos em igualdade de condições, como participantes no diálogo digital. Por um lado, tudo se transforma em seu filme: animais, pessoas, danças. Há metamorfoses constantes, nada pode permanecer cristalizado ou fossilizado, como se Masayesva quisesse mesmo mostrar a evolução de seu povo. Por outro lado, há uma denúncia explícita em relação aos filmes de Hollywood (que pode se estender a outros contextos também), cujos produtores e diretores manipularam e criaram estereótipos em relação à cultura indígena. Nesta parte, há um certo conservadorismo, especialmente no que se refere aos objetos sagrados e aos cultos. É como se Masayesva permitisse que seu povo se libertasse de seu passado, mas por livre e espontânea vontade, nunca pelos atos dos brancos. Há, então, também um double standard (jogo duplo), híbrido, que funde elementos das duas culturas e em certas circunstâncias valida o mesmo ato para alguns e o invalida para outros.

O aspecto híbrido do filme de Masayesva lhe confere a possibilidade de ser considerado principalmente como produto artístico. Cada vez mais, e com maior densidade e intensidade, os textos híbridos estão ganhando destaque a ponto de exigir novas leituras interpretativas e uma nova metodologia analítica, não só em festivais mas também nos círculos críticos e culturais. O cinema brasileiro tem também um representante do documentário híbrido que se destaca pelo seu ponto de vista diversificado: O Rap do Pequeno Príncipe contra as Almas Sebosas, de Paulo Caldas e Marcelo Luna. Filmado como se a câmera fosse um voyeur vagando rizomaticamente pelas vielas de Pernambuco 
e se incorporasse a cada transeunte-personagem, o filme traz a versão subjetiva do "justiceiro" Helinho, de 21 anos, acusado de matar 65 pessoas, e conhecido como "pequeno príncipe", de sua mãe, de policiais e advogados, e de Garninzé, de 26 anos, integrante da banda "Faces do Subúrbio", transformando-se em um grande hipertexto, onde as vozes refletem a multiplicidade de pontos de vista, não só dicotômicos mas também de uma variedade considerável.

Quanto ao aspecto híbrido, fica problemático falar da hibridação dentro do documentário, se compararmos com a hibridação do primeiro caso aqui analisado. As imagens de síntese podem ser consideradas híbridas com mais facilidade do que os documentários, pelo simples fato que os últimos trazem uma controvérsia ontológica, filosófica, do que se considera verdade e do que pode ser ficção. Aspectos factuais se transformam rapidamente em ficcionais ao serem recontados e representados. Como no caso da fotografia, que já serviu de prova documental em tribunais, o documentário atualmente pode ser analisado mais pelo seu valor artístico do que pelo seu aspecto referencial. Por outro lado, é o processamento digital que mais problematiza a referencialidade. Como define Arlindo Machado:

Dentre todas as imagens figurativas, a imagem eletrônica é a que menos manifesta vocação para o documento ou parao "realismo" fotográfico, impondo-se, em contrapartida, como intervenção gráfica, conceitual, ou, se quiserem, "escritural": ela pressupõe uma arte da relação, do sentido e não simplesmente do olhar ou da ilusão (Machado, 1997, p. 249).

Parte da simulação obtida pela imagem eletrônica se deve ao uso de fractals, que podem ser moldados à semelhança dos fenômenos naturais, gerando assim imagens híbridas, criadas por computador mas com referente real. Para Mandelbrot, "a geometria fractal é caracterizada pela relação entre a escolha de problemas no seio do caos da natureza e a escolha de instrumentos no seio das matemáticas "(Mandelbrot, 1984, p. 203). A geometria fractal, sendo não-euclidiana e não-linear, trabalha com frações e não números inteiros, podendo assim obter superfícies modeladas, irregulares, simulando a desordem natural, criando imagens metamórficas. 


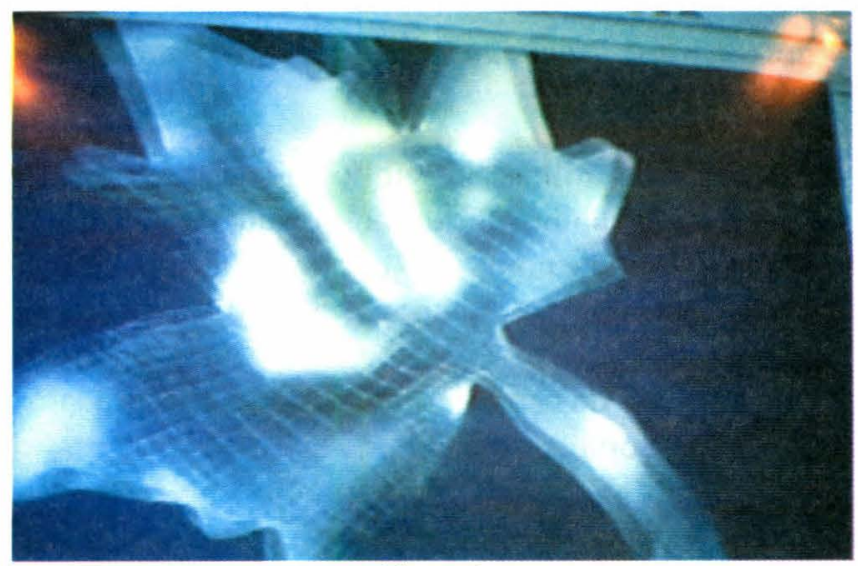

Figura 6

O making of do comercial Incandessence, novo perfume da Avon apresentado em rede televisiva, mostra como as folhas foram desenhadas usando formas fractais para simular o movimento de respiração e oferecer a sensação de leveza e frescor (fig. 6). Quando a modelo que usa o perfume passa perto das folhas caídas no solo, estas a seguem, coloridas e esvoaçantes. Feito em animação em 3D, o objetivo da escolha das formas fractais é despertar o imaginário e provocar percepções. O efeito criado pode responder afirmativamente à pergunta de Mandelbrot se a matemática se relaciona com a arte. Criador da geometria fractal, Mandelbrot explica que os fractais são formas geométricas que só foram possíveis depois do aparecimento do computador, e complementa:

A arte fractal exemplifica alguma coisa completamente nova: a atuação mútua de ordem e surpresa não precisa ser o resultado nem de imitação da natureza nem da criatividade humana: pode também ter uma fonte inteiramente diferente. De fato, fórmulas matemáticas extremamente simples que parecem completamente estéreis podem dar vida, por assim dizer, a uma quantidade de estruturas gráficas enorme. $O$ gosto do artista só pode afetar a seleção de fórmulas a serem 
desenhadas, o enquadramento e o desenho. (Mandelbrot, 1999 , p. 200)

No caso das folhas na publicidade da Avon, o processo poderia ser analisado como hibridação, considerando que o elemento natural a ser simulado é composto por uma fórmula geométrica. A espiral de folhas é mais realista que a própria realidade, é uma hiperrealidade.

Outro efeito de espiral criado com a utilização do recurso time slice é o do comercial do chocolate Suflair (figs. 7 e 8), da Nestlé, onde o objetivo não é simplesmente representar mas "fazer sentir" a sensação do chocolate "aerado". No comercial, a porta parece se derreter com a entrada da jovem, e quando o casal se encontra, seus corpos se entrelaçam, transformando-se em uma verdadeira espiral que parece se dissolver no ar. Enquanto Paulo Vainer, diretor de arte e fotógrafo do comercial, cria o clima onírico e sen-sual combinando os matizes vermelho e marrom da embalagem e misturando elementos neoclássicos e ultramodernos, a equipe da Casablanca, comandada por Reinaldo Pina, explica que a distorção é um processo híbrido que tem que contar com a atuação dos atores e a intervenção da técnica: É como se recortássemos cada uma das linhas da imagem e atrasássemos um frame. Assim a imagem se desloca para o lado e temos a distorção. Esse processo de recorte, atraso e colagem das imagens é feito automaticamente pelo computador". Pina acrescenta que a precisão do efeito é diretamente ligada à maneira como os atores encenam: "Dependendo do movimento deles, o efeito poderia sair de um jeito ou de outro. Se houvesse um pequeno movimento errado, a distorção poderia ficar comprometida" (Vainer, 2000, p. 31). 


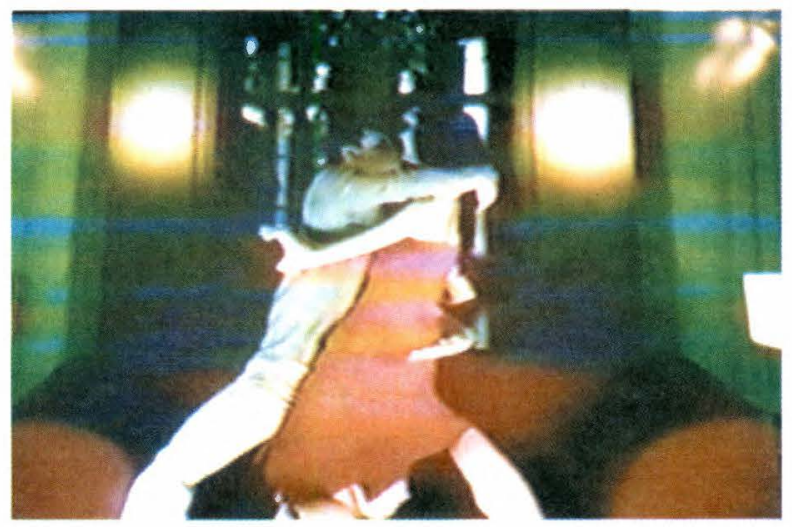

Figura 7

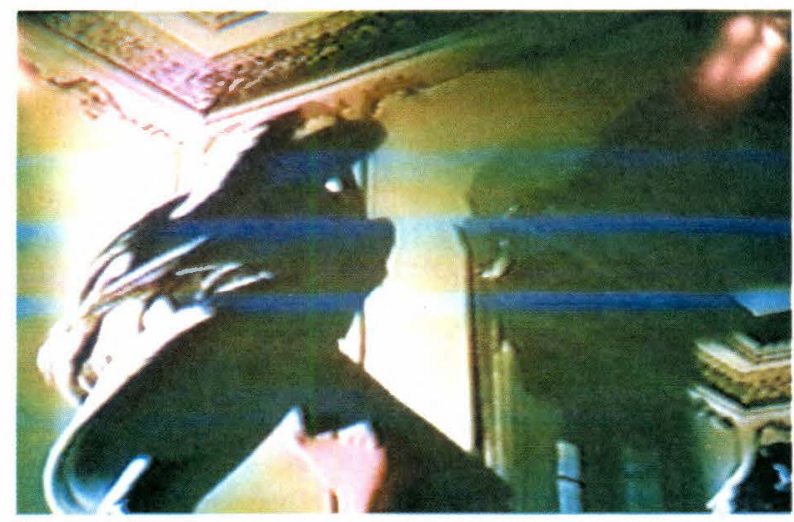

Figura 8

Essa hibridação atores-computador gera uma interação de ambas as partes para um efeito artístico. Mais uma vez, a estética da hipervenção se aplica, visto que o comercial, embora ambientado em um espaço real, cria a sensação de virtualidade, corroborada pela entrada da moça pela porta que se derrete, pela sensação lúdica criada pelo envolvimento do casal, pela espiral de corpos, e pela interação e hibridação de formas. Como define Michel Bret: 
A imagem das realidades virtuais, mais do que uma imagem, é uma sensação (visual, auditiva, cinestésica...), seu tempo é aquele da vida, mas de uma vida simulada, isto é, de uma réplica simbólica do mundo real. Longe de ser uma memória, ela se desenvolve numa duração que não é mais aquela do momento, mas a da simulação (Bret, 1997, p. 105).

O comercial, aliando atuação e tecnologia, atualiza a sensação "aerada" e a interação sinestésica cromatismo-sabor, como se a moça de vermelho e pele morena não só fosse a metáfora do chocolate mas se metamorfoseasse no próprio, dando ao seu consumidor a sensação sensorial visual-gustativa.

A produção em vídeo tem também produzido formas híbridas. Nunca fui santa, de Claudia Guimarães, é um vídeo feito com fotografias de trinta e uma estatuetas de freiras coroadas com arame farpado. A artista plástica Tutti Stocco e a cineasta Claudia Guimarães pintaram imagens de freiras e as alinharam como um pelotão de exército. As fotos foram tiradas, então, de ângulos diferentes,passando a compor vinte e quatro quadros. Na ediçãocomputadorizada, o tempo de cada foto foi dado pelo ritmo da trilha de Arnaldo Antunes. A narrativa da imagem é, assim, determinada pelo texto, tendo a fotografia como matéria-prima. Cada foto é um plano, parte de uma seqüência única, mas a impressão é de que há cortes secos depois de cada foto. O formato videoclip contribui para a hibridação, visto que não se pode dizer que este trabalho de Claudia Guimarães seja um vídeo, na acepção do termo, ou um videoclip para a trilha de Arnaldo Antunes, ou uma obra experimental multimídia. A hibridação foto-vídeocomputador rejeita classificações fixas e dessacraliza tanto o aspecto semântico do conceito de "santidade", com suas conotações de "pureza e singeleza", como as convenções da falsa ilusão do movimento cinematográfico. Na edição computadorizada, é o computador que dá o tempo de duração de cada foto, de acordo com o tempo da trilha sonora.

Talvez aqui se possa dizer que a fusão imagem-trilha seja tão perfeita quanto os produtos finais das imagens de Nick Knight, no sentido de não se poder enfatizar que as imagens foram construídas para ilustrar a trilha nem vice-versa. A fusão se dá no nível semântico, 
pela repetição das imagens e dos verbos representativos das ações cotidianas, e no semiótico, pelo ritmo contínuo que une imagem e trilha. A estética da hipervenção mais uma vez se aplica, considerando que a intervenção do computador vai integrar elementos dentro de um espaço virtual fotográfico, com um tempo que poderia se estender ad infinitum.

Ainda dentro do universo fotográfico, é importante ressaltar os textos híbridos de Margaret Benyon e de William Wegman, que hibridizam elementos característicos de animais e de seres humanos (figs. 9 e 10). Enquanto textos híbridos, ambos combinam elementos, mas o texto de Benyon, Tigirl (garota-tigre), parece enfatizar mais o elemento mulher, com intertextos de tigre, ao passo que Wegman é famoso por seu trabalho com cães Weimaraners, dando-lhes características humanas. Ambos têm em comum o objetivo de combinar elementos aparentemente contraditórios, produzindo textos criativos que remetem a novos tipos de leituras.

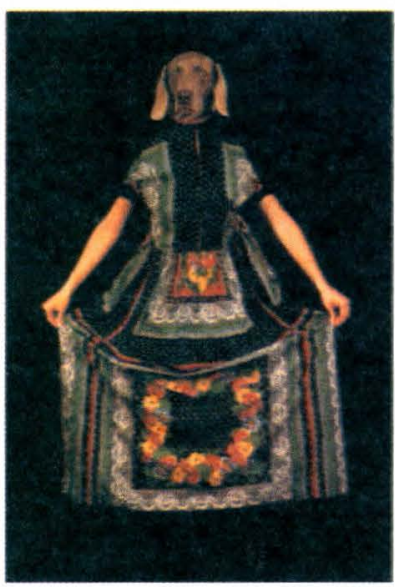

Figura 9

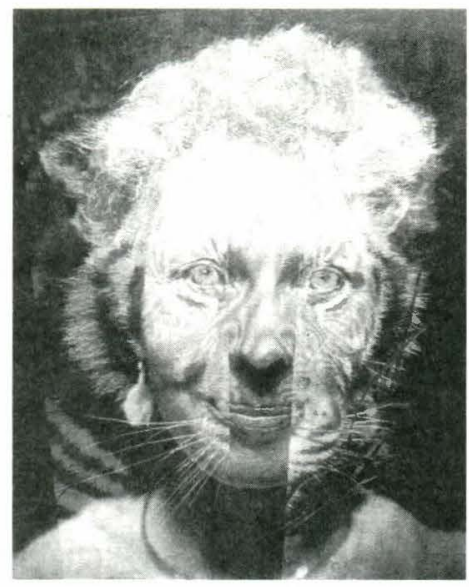

Figura 10

No universo das formas híbridas, entretanto, há uma modalidade que tem se destacado: a arte transgênica de Eduardo Kac. Seu projeto Ornitorrinco, como ele mesmo diz, está "em constante mutação", e provavelmente "continuará a gerar formas híbridas 
que combinam tecnologias mais velhas com pesquisas recentes" (Kac, 1997, p. 322). Acredito que suas experiências mais ousadas, no entanto, são as relacionadas com mudanças genéticas, como seu coelho e seu cão verdes (fig. 11). Kac descobriu que a GFP (Green Fluorescent Protein, ou Proteína Verde Fluorescente) emite uma luz verde brilhante, como neon, que, aplicada ao embrião de um cão (canine, jocosamente K-9), o fará emitir raios verdes de acordo com a iluminação do ambiente. De acordo com Arlindo Machado, o cão transgênico e fluorescente,

que ilumina o ambiente com sua luz verde, o cão 'sublime', essa espécie de obra de arte viva, poderia ser apenas mais uma etapa da intervenção do homem na evolução do animal que historicamente sempre esteve mais próximo dele (Machado, 2000, p. 2).

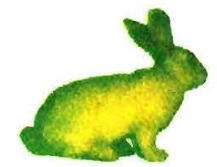

Figura 11

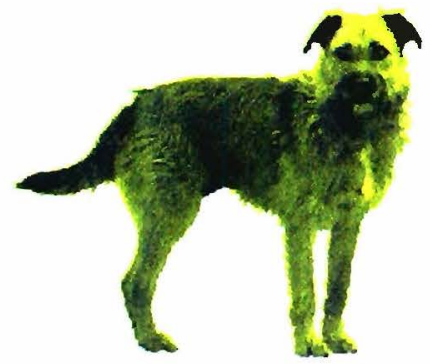

GFP-K9, Eduardo Kac (in progress)

Estas pesquisas de Kac ainda estão em desenvolvimento, assim como minha análise no que se refere à arte transgênica.

Em síntese, as formas híbridas são novos tipos de linguagem que se comunicam entre si em processos de fusão ou interação. Acredito que a área é vasta, e que as pesquisas estão dando os primeiros passos, trazendo visões apocalípticas ou opiniões entusiasmadas. Para André Lemos,

a hibridação (espaço, tempo e corpo) parece ser o paradigma das artes eletrônicas desse fim de século. A ciberarte é assim 
uma arte interativa híbrida, existindo um movimento contínuo : de passagem do espaço físico ao eletrônico, do córpö fisico ao corpo-prótese, do tempo subjetivo e individual ao tempo imediato (real). O qúe está em jogo é umà certa "edição da realidade (edição da sociedade de espetáculo?), a pairtir de sèus múltiplos fragmentos. (Lemos, 2000, p. 239)

O que se pode prever é que o avanço das novas tẻcnologias abrirá, sem dúvida, novos campos de conhecimento e um imenso espáço para o desenvolvimento de novos conceitos sobre o potencial humano e tecnológico.

\section{Bibliografia}

BARTHES, Roland. 1981. Camera Lucida: reflections on photography, trans. Richard Howard. New York: Hill and Wang.

BRET, Michel. 1997. "O tempo reencontrado". In: DOMINGUES, Diana (org) A arte no século XXI: a humanização das tecnologias. São Paulo: UNESP, pp. 102-107.

KAC, Eduardo. 1997. "A arte da telepresença na Internet". In: DOMINGUES, Diana (org) $A$ arte no século XXI: a humanização das tecnologias. São Paulo: UNESP, pp. 315-324

LEMOS, André. 2000. "Arte eletrônica e cibercultura”. In: MARTINS, F. M. e SILVA, J. M. da (orgs) Para navegar no século XXI. Porto Alegre: EDIPUCRS, pp. 225-243.

MACHADO, Arlindo. s/d. "Fotografia em mutação". Nicolau, ano VII, no. 49: 14-15.

. 2000. "Por uma arte transgênica" www.ekac.org/ arlimachtrans.html, 29/8/2000. Ed.

MANDELBROT, Benoit. 1984. Les objects fractals. Paris: Flammarion.

1999. "Fractais: uma forma de arte a bem da ciência". In: PARENTE, André (org) Imagem máquina. São Paulo: Ed. 34, pp. 195-200. 
PLAZA, Julio.1999. “As Imagens de terceira geração, Tecno-poéticas”. In: PARENTE, André (org) Imagem máquina. São Paulo: Ed. 34, pp. 72-88.

\& TAVARES, Monica. 1998. Processos criativos com os meios eletrônicos: Poéticas digitais. Șão Paulo: Hucitec.

POPPER, Frank.1999."“As imagens artísticas e a tecnociência”. In: PARENTE, André (org) Imagem máquina. São Paulo: Ed. 34, pp. 201-213.

PRINCE, Stephen. 1996. "True lies: perceptual realism, digital images, and film theory." Film quarterly, v.49.\#3, Spring, pp. 27-37.

QUÉAU, Philippe. 1999. “O tempo do virtual”. In: PARENTE, André (org) Imagem máquina. São Paulo: Ed. 34, pp. 91-99.

VAINER, Paulo. 2000. "Morena". Tela viva, outubro, 31.

WEISSBERG, Jean-Louis. 1999. "Real e virtual". In: PARENTE, André (org) Imagem máquina. São Paulo: Ed. 34, pp. 117-126. 